\title{
Telemetric Remote Monitoring of Cardiac Devices. Is the Future of Medicine a Liability Trap for the Physician?
}

\begin{abstract}
Objectives: Telemetric remote monitoring of cardiac pacemakers and implanted defibrillators constitutes significant medical-technical progress and an improvement of healthcare. However, for the cardiologist providing aftercare, this also incurs liability risks which he should be aware of and take into consideration. This article presents the reason for and limits of said liability and of the responsibility of the acting cardiologist. The cardiologist is aware of his risks and is advised on how to avoid them.
\end{abstract}

Methods: The legal situation is examined from the perspective of continental European legal tradition, namely from the German and Italian perspectives. The authors examine both aspects in Penal Law as well as in Civil Law and show which agreements and patient information can minimize the liability risks for the cardiologist.

Results: The article clarifies whether alarms only need to be evaluated during consultation hours and what consequences arise if data transmission does not occur or the cardiologist is unable to receive the data. Furthermore, the patient's cooperation duties for the individual products and the significance of a patient information talk with the doctor are elucidated.

Conclusions: Although the medical side, including patient satisfaction and economic aspects, is well backed-up internationally, expert legal literature has not yet adequately addressed the problem. However, no "telemetry law" is required, the legal issues can be solved within the established liability and responsibility category and the terms of "breach of duty of care"/"imperizia". The following paper lines out the SOP, a doctor has to follow it to avoid liability and to ensure that patients have benefits from telemetric remote monitoring.

Keywords: Telemetry - Manslaughter - Negligent bodily injury - Remote monitoring - Cardiac defibrillator - Cardiac pacemaker - Duty of care - Liability, Response time - Inspection duty Intervention duty

\section{Saving Lives Through Technical Progress}

It is Saturday, just before sundown and Dr. Rossi, a cardiologist, is enjoying an aperitif on a sailboat off the Sardinian coast. At last, no more Internet, alarms or patients. After a relaxing weekend he anchors in the harbor. The app on his cellphone now alerts him to an emergency call just placed, which he receives instantaneously: "Patient Z, male, 60, 40\% risk for inadequate shocks within the next $24 \mathrm{~h}$ ".
Hendrik Schneider* and Martina Orrù

Büro für Gutachten und Strafverteidigung, Taunusstrasse 7, Wiesbaden, Germany

*Author for correspondence: Tel.: +49 (0) 61153165841 schneider@hendrikschneider.eu Submitted: March 06, 2018 Accepted: March 16, 2018 Published online: March 23, 2018 
This example apparently corroborates the stance of the advocates of technology and digitalization [3] in modern medicine, as in the case of such a defect of the device, e.g. through damage of the electrodes, there is the risk that the defibrillator will falsely assume an indication of a shock for regularization of the cardiac activity. In such a case, the life of the patient would have been in grave danger [4]. This type of malfunction of the devices is not the exception. According to a study by the Federal Drug Administration (FDA) the annual average quotas of reimplantations due to a malfunction of the device range from 1.4 and $9 / 1000$ for the patients equipped with a cardiac pacemaker and 7.9 to $38.6 / 1000$ of the ICD patients for cardiac defibrillators. The actual number of defects is estimated to be triple that of the reimplantation rate [5].

Telecardiology (in the form of telemetric functional analysis) not only protects against the risks of malfunction of the device but may also support the treatment of the patient [6]. Because in addition to the technical data of the device, depending on the model being used, additional information can also be relayed, such as course and frequency of atrial fibrillation, average heart rate, heart rate variability etc. This is known in this context as intricate, complete remote monitoring of technical and clinical patient data.

A number of studies provide evidence that telemetric care of patients entails a significant general improvement of care quality (with regard to the safe operation and the setting of the units and patient management [7]). The currently applicable guideline [8] as well as a European-American consensus document [9] clearly recommend implant-based telemonitoring after evaluation of empirical data. For this reason, the Heart Rhythm Society (HRS) established a mandatory Class I indication (Evidence Level A) on the basis of the scientific research results.

In this context Topols is willing to consent to the basic assumptions voiced in 2010:

"digital medical devices... have exceptional promise for changing the future of medicine [...]." [10]

The third (digital) industrial revolution [11] has long arrived in the field of medicine, changing the everyday lives of not only the patients, but of the doctors as well. In the area of telecardiology and in particular of remote monitoring of the corresponding devices the consequences of technical development can generally be rated positively. It is not only the sample case that proves this. Even in countries with good basic medical care in which such products are part of the spectrum of healthcare services there is often an acute dearth of specialized doctors, or transportation is inconvenient for the senior patients restricted in their mobility. Use of the respective products can extend the intervals until the next visit to the specialist, making the patient's everyday life more convenient and taking a burden off the healthcare system [12]. This is compounded by an increased feeling of security for the patient exerted by an electronic "connection" to his doctor [13]. Positive financial effects which could offset the additional costs of devices with telemetric remote monitoring can likewise be expected with increasing acceptance of the products on the market.

\section{Liability Risks-Issues Addressed in the Article}

The actual changes meet with legal challenges in addition to economic ones. For example, what does it imply when implantable defibrillators with telemetric remote monitoring alert the doctor when he is on vacation as in the sample case or, on the weekend that the risk of an inadequate shock discharge has currently increased? What are the consequences when patients fail to comply with their cooperation duties in data transfer and for this reason malfunctions of the system or changes in health are not communicated? The article addresses these issues from the perspective of the Continental European legal system using the example of Germany and Italy.

\section{Basis for Liability in Civil Law and Responsibility under Penal Law}

The foundations of the liability categories in German and Italian Civil Law as well as Penal Law can be traced back to a time prior to the switch to "Fordist production technology" and long before digitalization. German Penal Law and its categories is based on the Reichsstrafgesetzbuch of 1871 (Imperial Penal Code) and the Bürgerliches Gesetzbuch (Civil Code) was enacted on Jan. 1, 1900. The legal situation in Italy is similar but the basic laws are somewhat more recent. The Codice Penale (C.p.) is from 1930, the Codice Civile (C.c.) from 1942. Despite the relative age of the applicable laws the abstract categories and benchmarks of responsibility under Penal Law and liability under Civil Law are adequate for answering most of the questions related to the use of telemedicine and telecardiology. There are currently however no in-depth legal treatises on the issues or court rulings from which guideline principles or benchmarks can be derived.

Both legal systems and legal subjects essentially 
assume a "corpus delicti" in the case of liability under Penal Law and liability under Civil Law and examine within the scope of causal "regressus ad personam" to what extent damage to health or onset of death can be attributed to the actor or omittor. Both under Penal Law and Civil Law risks are only incurred to the cardiologist if the patient has died or his health was impaired beyond the underlying illness but not where the potential breach of duty of care [14] was without consequences. Thus, there must cumulatively be a breach of duty of care and damage to the patient's legal assets (i.e. life or health as links to circumstances constituent of manslaughter [15] or negligent bodily harm [16]) in order to incur liability by the doctor [17] and responsibility under Penal Law.

Only under Italian law does a ground for exclusion of punishment of "negligent responsibility for death and bodily injuries in the area of health" apply to responsibility under Penal Law since the Gelli-Bianco [18] (of Mar. 8, 2017) in Art. 590. According to this, prosecutability (Punibilità) is excluded when the doctor acted in accordance with the applicable guidelines or, if there are no such guidelines, in compliance with the rules of "good clinical practice".

In the sample case Dr. Rossi responded immediately. He acted in compliance with his duty of care, preventing the danger exerted by the defective device from running into damage to the patient's legal assets. There is neither a breach of duty of care nor damage. Thus, liability under Civil Law (in the form of breach of duty of the treatment contract with the patient and of an illegal act) is excluded as liability under Penal Law.

However, Dr. Rossi would be subject to responsibility under Penal Law or Civil Law if he had failed to avert the danger, an actual non-indicated shock had occurred, causing harm to the patient. If in contrast there is no damage despite a breach of care Dr. Rossi is not liable either. Because solely negligent danger to health does not constitute an offense or liability under Civil Law. It is a different case where the doctor willfully omits a reasonable action. In such a case he is indeed prosecutable and liable if the risk does not materialize and death or damage to health does not occur. But such a case will not be relevant in practice. Hypothetically, Dr. Rossi could be held liable under these circumstance for example if he was indifferent to his patient's life and did not ask for help via his cellphone because he did not want his weekend disrupted.

The relevant questions are limited to constellations of a negligent cause of death or impairment of health.
The key aspect in this context is the issue of a breach of duty/lesione del dovere di diligenza. The cardiologist is only liable and prosecutable on grounds of bodily injury or manslaughter $(\$ \$ 222,229$ German Penal Code StGB/Art. 589 and 590 C.p.) if he breached his duty of care in the concrete situation.

Essentially, the specialist physician standard applies, a distinction being made between specific typified groups of errors such as information, diagnosis and therapy errors.

\section{Duties of Care of the Cardiologist when Using Devices with Telemetric Remote Monitoring}

\section{Response times and handling alarm notifications}

The question arises in the sample case in what period of time the doctor needs to respond to telemedical incident notifications in order to comply with his duty as a doctor and to avoid liability.

It is stressed in medical literature that telemetric remote monitoring of cardio defibrillators and cardiac pacemakers is not "an emergency response system". Slotwiner et al. state [19]:

"A frequently misunderstood limitation of RM is its inability to act as an emergency response system. Patients and caregivers should be made aware, that there is a delay between an episode or alert and that transmission of that alert CIED clinic. The CIED clinical organizational model should also not be constructive to immediately interpret an act on alerts; rather it should do so within an acceptable timeframe (such as the next business day). Information on the expected reaction times should be carefully explained to patients, and they and their caregivers should be instructed on how to react in an emergency situation.... A number of institutions have formalized the process ask patients to sign agreements. These serve as documentation of the patient's education process and reinforce patient expectations. Patients should also be given explicit instructions on how to interface with the CIED follow-up clinic when experiencing symptoms".

The only consequence of this is that implantbased telemonitoring systems, though good for early detection, may not emit emergency signals or be used as an emergency system. In this way, neither patients nor the doctors providing treatment and the nursing staff can rely on the fact that no alarm was emitted and ignore any other symptoms but are obligated to inspect them. However, the conclusion that the cardiologist receiving a device alarm could remain passive or react 
with delay because there is no emergency system in the device cannot be drawn from this.

This follows from the legal nature of the breach of duty of care which constitutes an omission if the cardiologist remains passive. The treatment contract with the patient [20] under his outpatient care obligates him to do what is necessary on his part to avert the danger. This can be concluded from $₫ 13$ of the German $\mathrm{StGB} /$ the comparable Art. 40 of the Italian C.p. Both laws obligate the guarantor (i.e. in the present case the doctor) to do all that is necessary to avert danger to his patient. In the present case, Dr. Rossi complied with this duty. He adequately responded to the alarm by the device, acting in compliance with the law. Had he in contrast waited until Monday morning, impairing the patient's health or causing his death, Dr. Rossi could not have been able to defend himself with the argument that remote monitoring is not "an emergency response system."

From the aspect of Penal Law and Civil Law, for determining response time the patient's risk situation is particularly important. The latter can be derived from the type and severity of the basic illness as well as cause of the alarm. As soon as the physician detects a concrete risk situation of the patient on the basis of these parameters he is obligated to act. In the sample case what matters is that a non-indicated shock triggered by the device is associated with 2.3 times greater mortality according to medical findings and for this reason the patient's life may be in danger depending on his health condition [21]. Essentially, liability risks with regard to response times to reported incidents can hardly be limited with certainty. They are always a question of the individual case and depend on the aforementioned parameters. Failure to act by the doctor or a delayed response to the alarm is thus a treatment error in the form of a therapy error.

\section{Limits of the response duty on the basis of the treatment contract}

The problem of the response time depicted above ties into the fact that the cardiologist receives the alarm by the device and accordingly is aware of the imminent danger to his patient. In this case the duties to act are triggered by the identification of the danger. What must be differentiated in this case is the question as to whether in principle the cardiologist is obligated to ensure that he receives alarm notifications outside of his consultation hours, i.e. on the weekend or at night or during his vacation. In the sample scenario for example, instead of receiving the alarm in the harbor, Dr. Rossi might get it at sea where there is no reception. If he does not get the alarm before arrival at the harbor it may be already too late for the patient. Under liability law and penal law this raises the question as to whether the case is any different from the situation where Dr. Rossi responds too late to the alarm. Is he also acting in breach of his duty of care if he does not ensure that he can be reached at all times?

What must be examined is whether the doctor must provide an infrastructure in which alarms are registered, monitored and inspected with regard to their risk situation. From a medical standpoint this is certainly desirable, as only through constant monitoring can the potential of the device be fully exploited. From a factual standpoint, this protection of the patient could be ensured through cooperation between the doctor and the clinic.

According to current interpretation, from the legal standpoint the doctor is not obligated to provide absolute protection. The reason and limits of duties to act are set out in the treatment contract between the cardiologist and his patient. Under German Penal Law only warranty obligations and responsibilities for life and limb of another entail legal obligations [22]. Such legal obligations in the sense of duties of care may also be assumed by a contract [23]. Thus, the extent of the contractually assumed responsibility, of which the patient must be informed in a patient information talk, is decisive for liability. It is in the nature of outpatient treatment that healthcare is only ensured during the consultation hours of the doctor's office and that outside of these hours patients are referred to emergency care/hospitals. The doctor does not have to be accessible either by phone or personally outside of his consultation hours. In the case of a "full care assignment (fulltime work by the doctor) consultation hours in Germany must be held at least 20 hours per week for patients with public insurance.

If these criteria which make up the timeframe for the "analog" treatment of the patient are extrapolated to "digital" readiness it can be concluded that in the above sample case Dr. Rossi would even have been able to turn off his phone without the risk of liability if he fully informed his outpatient and the patient gave his consent. Where the device emits an alarm outside of the times guaranteed by the doctor and it is not received the doctor will not be liable or subject to responsibility under Penal Law if damage is incurred. However, if he receives the alarm he must act according to the principles depicted above. In this context, as well the principles 
and liability benchmarks from the analog setting can be extrapolated to the digital world. The cardiologist who finds the patient in an acute emergency situation during his leisure time is obligated to act. The treatment contract with the patient establishes an increased duty to avert the incident and the doctor can be prosecuted or held liable under Civil Law in the case of intent or even manslaughter through failing to act and not merely on grounds of failure to render assistance.

\section{Cooperation duties of the patient}

Failure to relay data: The patient has cooperation duties initially in the case of specific devices providing for transmission of the data by the patient (e.g. by placement of the scan head on the implant as data transmission initiated by the patient). In this context liability risks which could result from the cardiologist's failure to receive status reports from the device must be discussed. This was the situation in the case of an 83-year old patient: The patient was given an implant of a DDD cardiac pacemaker due to an AV block (heart arrhythmia with a variably marked blocking of the AV node/distally located structures of the heart's electrical conduction system. Over the next six years the specialist for Internal Medicine checked the pacemaker regularly (in the fifth year he noted down an anticipated residual life of 2.5 years for the device). As a consequence, there was no telemetric transmission because the patient forgot to have the data transmission carried out. This was not registered in practice" [24].

From the aspect of aftercare in accordance with the guidelines for cardiac pacemaker therapy, inspection of the pacemaker is an obligation of the doctor, defined specifically as follows:

"Due to the introduction and continuous further development of diagnostic and therapy options over the past several years, pacemaker systems have become increasingly more complex. Inspection of the pacemakers and optimal management of patients with cardiac pacemaker systems therefore pose an increasing number of challenges to the doctor providing aftercare: checking the proper functioning of the system, detecting and rectifying complications/malfunctions, extending the duration of the pacemaker, establishing the optimum time to exchange a system, individual optimization of the programmable parameters, adjustment of the diagnosis and therapy options available, decision regarding the necessary equipment of a pacemaker system (bicameral, CRT system, defibrillator). A pacemaker inspection is performed with the programming device by the manufacturer designated for the respective unit. [25]
The duties within the scope of aftercare for implanted defibrillators are described in a similar manner as in the guidelines for the implantation of defibrillators:

"Aftercare of patients with implantable defibrillators is intended primarily to ensure the correct function of the ICD system, but absolutely also to take into account the basic illness and its non-rhythm complications and therapy. Potential complications and malfunctions of the system are to be already detected and rectified before potential danger to the patient (e.g. dysfunction of the probe). Documentation and analysis of the arrhythmia episodes stored in the ICD is of key significance both regarding the medical status of the patient and as an indication of potential malfunction of the system. Integrating the information from diagnostic storages, an individual optimization of programmable parameters is conducted.... Subject matter of an ICD check-anamnesis, physical check-up, request of the ICD system, individual programming. The interpretation of the stored rhythmological episodes in the ICD in line with the patient's clinical studies is of key significance within ICD aftercare. Regular presentation: Generally, the check-ups take place every 3-6 months. The function parameters of the unit are checked. In addition, there is a general anamnesis including questions regarding mental state and a clinical status with ICD bags inspection."

Accordingly, "inspection of the functioning condition of the system" is a basic obligation of the cardiologist. The guideline does not refer to telemetry but the latter is to be regarded as an inspection variant within the scope of admissible telecare and therapeutic discretion. Against this backdrop, the cardiologist is subject to a duty of inspection with regard to the receipt of data, the breach of which constitutes malpractice [26].

Regarding the timeframe for the origin of the inspection obligation, information from the manufacturer may provide reference points. It is to be assumed that a time interval is authoritative for the inspection duty and not a point in time to be set for all conceivable individual cases.

Where the data is not provided, an intervention duty must be assumed. The breach of the intervention duty will also constitute malpractice. For this purpose, the communication channel agreed on with the patient or of which he was informed is to be used. To the extent that the cardiologist has failed to comply with this information duty set out in the contract and the patient was informed of the omission, gaps in or specific errors of data transmission, the principle of personal 
responsibility will apply. The doctor did what was necessary on his part, thus acting in accordance with the duty of care. If at the same time the patient does not visit him, this excludes liability by the doctor.

In the sample case with the 83-year old patient the doctor thus breached his inspection duty. As, according to the above principles, the doctor has the duty to inspect the functioning condition of the pacemaker, it is also irrelevant in whose sphere of responsibility the data transmission error lies. To the extent that there is a unit or system error, this might establish another party against whom claims can be asserted within the scope of joint and several liability. To the extent that the patient, as discernible in the case, failed to comply with his duties of cooperation, this does not remove the onus from the doctor, as the latter has an independent inspection duty within the scope of the treatment contract and it is independent of the source of trouble.

\section{Insufficient information on duties of cooperation}

The doctor is obligated to inform the patient of all circumstances that are essential to treatment [27]. The doctor's information duty comprises the duty to completely inform the patient that he needs to support the telemedicine treatment if necessary through cooperation. The doctor will only have complied adequately with this duty if he has gained the impression on the basis of adequate indications that the patient has understood both his cooperation duty as well as the conduct recommended by the doctor [28]. The reason for this duty is the doctor's superior knowledge to that of the patient. Where the doctor fails to comply or

\section{References}

1. https://www.sciencedirect.com/science/article/pii/ S1532046412000287

2. Schneider H, Bosch R, Ebermann T, et al. Ist ein Kardiologe immer im Dienst?! Haftungsrisiken beim Einsatz und Nichteinsatz telemetrischer Fernüberwachung von Kardiodefibrillatoren und Herzschrittmachern. Aktuel Kardiol 5(02): 1-4 (2016).

3. Torkamani A, Steinhubl SR, Topol EJ. High-Definition Medicine. Cell. 170: 828-843 (2017).

4. See facts of the case in the ruling by Hamm Higher Regional Court of Nov. 6. (Case No. 1 U 48/07 (2008).

5. Maisel WH, Moynahan M, Zuckerman BD, et al. Pacemaker and ICD generator malfunctions: analysis of food and drug administration annual reports. JAMA. 295: 1901-1906 (2006).

6. Stockenburger M, Helms TM, Perings CA, et al. Nutzenbewertung des strukturierten Telemonitorings mithilfe von aktiven Herzrhytmusimplantaten. Kardiologe. 11: 452-459 (2017). comply completely with this, this constitutes a breach of duty which may incur a case of liability [29].

\section{Conclusion}

The cardiologist does not have to be afraid of the law when using telecardiology.

Despite the relative age of the applicable laws the abstract categories and benchmarks of responsibility under Penal Law and liability under Civil Law are adequate for answering most of the questions related to the use of telemedicine and telecardiology. No new statutory provisions are therefore required either to limit the liability risks.

From the legal standpoint the doctor is not obligated to provide a $24 \mathrm{~h}$ service, 7 days a week. The reason and limits of duties to act are set out in a detailed agreement contract between the cardiologist and his patient. Healthcare is only ensured during the consultation hours of the doctor's office where the doctor must provide an infrastructure in which alarms are registered, monitored and inspected. Outside of these hours the doctor does not have to be accessible either by phone or personally and patients are referred to emergency care or hospitals. Where the device emits an alarm outside of the times guaranteed by the doctor and it is not received the doctor will not be liable or subject to responsibility if damage is incurred. However, if he receives the alarm he must act according to the principles depicted above and promptly act.

The protection of the patient could be ensured and extended also through cooperation between the doctor and a clinic, which offers a $24 \mathrm{~h}$ service.

7. Hilber T, Helms TM, Mikus G, et al. Telemetrie im klinischen Umfeld. Herzschr Elektrophs. 19: 146-154 (2008).

8. Brignole M, Aurrichio A, Baron EG, et al. ESC Guidelines on cardiac pacing and cardiac resynchronization therapy. Eur Heart J. 34(29): 2281-2329 (2013).

9. Dubner S, Auricchio A, Steinberg JS, et al. ISHNE/ EHRA expert consensus on remote monitoring of cardiovascular implantable electronic devices (CIEDs). Europace. 14(2): 278293 (2012).

10. E. J. Topol. Transforming medicine via digital innovation. $S c i$ Transl Med. 2: $16 \mathrm{~cm} 4$ (2010).

11. Suesskind R, Suesskind D. The future of the professions: How technology will transform the work of human experts. (2015).

12. Slotwiner D, Varma N, Akar JG, et al. HRS Expert Consensus Statement on remote interrogation and monitoring for cardiovascular implantable electronic devices. Heart Rhythm. 12: e69-e100 (2015).

13. Masoudi F, Calkins H, Kavinsky C, et al. ACC/HRS/SCAI 
left atrial appendage occlusion device societal overview. Heart Rhythm. 12(10): e122-e136 (2015).

14. http://www.altalex.com/documents/news/2014/12/09/del-reato

15. https://www.gesetze-im-internet.de/englisch_stgb/englisch_ stgb.html\#p1870

16. https://www.gesetze-im-internet.de/englisch_stgb/englisch_ stgb.html\#p1913

17. https://www.brocardi.it/codice-civile/libro-quinto/titolo-iii/ capo-ii/art2236.html/

18. http://www.senato.it/leg/17/BGT/Schede/Ddliter/ dossier/46445_dossier.htm

19. Ricci RP, Calcagnini G, Castro A, et al. Documento di consenso sul monitoraggio remoto dei dispositivi impiantabili: tecnologie disponibili, indicazioni, modelli organizzativi, accettabilità, responsabilità ed aspetti economici. Associazione italiana di Aritmologia e Cardiacstimolazione. Area di Telecardiologia. $G$ Ital Cardiol. 12(6): 450-467 (2011).

20. https://www.gesetze-im-internet.de/englisch_bgb/englisch_bgb. html\#p2651

21. Borne RT, Varosy PD, Masoudi FA. Implantable cardioverterdefibrillator shocks: epidemiology, outcomes, and therapeutic approaches. JAMA Intern Med. 173(10): 859-65 (2013).
22. https://www.gesetze-im-internet.de/englisch_stgb/englisch_ stgb.html\#p0107

23. Schneider H, Gottschaldt P. Offene Grundsatzfragen der strafrechtlichen Verantwortlichkeit von ComplianceBeauftragten in Unternehmen. ZIS: 573-577 (2011).

24. https://www.gesetze-im-internet.de/englisch_stgb/englisch_ stgb.html\#p2779

25. Foth E, Hespeler U, Felsenstein M, et al. Verantwortlichkeit des Kardiologen für die Kontrolle des Herzschrittmachers bei Telemetrie. Landesärztekammer Baden-Württemberg (2015).

26. Lemke B, Nowak B, Pfeiffer D. Guidelines for pacemaker therapy. J Cardiol. 94: 704-720 (2005).

27. Dierks C, Feussner H, Wienke A. Für Fehler bei der Datenübermittlung haftet die Behandlungsseite, falls es sich um Softwarefehler handelt, in Konkurrenz mit Ansprüchen gegen den Hersteller aus dem Produkthaftungsgesetz und der Produzentenhaftung. Rechtsfragen der Telemedizin. p. 64 (2013).

28. https://www.eu-patienten.de/en/rechtsquellen/bgb_630e_ aufklaerungspflichten.jsp.

29. Ricci RP, Morichelli L, Onofrio A, et al. Effectiveness of remote monitoring of CIEDs in detection and treatment of clinical and device-related cardiovascular events in daily practice: the HomeGuide Registry. Europace. 15(7): 970-977 (2013). 